Check for updates

Cite this: J. Mater. Chem. B, 2019, 7, 1149

Received 20th November 2018, Accepted 17th January 2019

DOI: $10.1039 / c 8 t b 03054 \mathrm{e}$

rsc.li/materials-b

\section{Self-assembly of nanoparticles by human serum albumin and photosensitizer for targeted near-infrared emission fluorescence imaging and effective phototherapy of cancer $\dagger$}

\author{
Yan Huang, ${ }^{\mathrm{ab}} \mathrm{Na} \mathrm{He},{ }^{\mathrm{b}}$ Yunqing Wang, ${ }^{\mathrm{b}}$ Dazhong Shen, (D) a Qi Kang, *a \\ Rongfang Zhao ${ }^{b}$ and Lingxin Chen $\mathbb{D}$ *bc
}

\begin{abstract}
Photodynamic therapy (PDT) and photothermal therapy (PTT) are effective cancer treatments, and photosensitizers play the most important role in the treatment. However, photosensitizers are insufficient for in vivo tumor treatment. Herein, we develop a small molecule fluorophore Cy-HPT as a novel photosensitizer, which possesses the advantages of near-infrared (NIR) emission, high photothermal conversion efficiency and high singlet oxygen generation efficiency. Moreover, a nanoplatform of HSA@ Cy-HPT was synthesized by self-assembly of Cy-HPT and human serum albumin (HSA) in aqueous solution. Compared to Cy-HPT, HSACCy-HPT possesses more stable spectral properties, enhances the effect of PDT/PTT, and exhibits more satisfactory in vivo metabolism. HSACCy-HPT demonstrates outstanding tumor targeting in subcutaneous tumor xenograft models owing to its enhanced permeability and retention in tumor tissue. Furthermore, HSA@Cy-HPT was successfully utilized in tumor xenograft models and tumor tissue growth was clearly inhibited without any regrowth, extending survival rate of the models. Also, no distinct damage of the normal tissue of tumor xenograft models was observed using hematoxylin $\&$ eosin staining. This study presents a promising therapeutic agent for the synergetic PDT and PTT cancer treatment.
\end{abstract}

\section{Introduction}

As the incidence of cancer and death rates associated with it remain high, innovative therapeutic strategies are imperative. Conventional treatment of cancer includes a combination of surgery, radiotherapy, and chemotherapy. Photodynamic therapy (PDT) and photothermal therapy (PTT) are promising therapeutic techniques owing to their high curative effect, low toxicity and negligible side effects. ${ }^{1-3}$ Photosensitizers play a key role in both PDT and PTT. On one hand, they are generally excited under light irradiation to produce singlet oxygen $\left({ }^{1} \mathrm{O}_{2}\right)$ species owing to the photophysical conversion phenomena. ${ }^{4}$ ${ }^{1} \mathrm{O}_{2}$ not only oxidizes proteins and generates free radicals and other bioactive molecules in cytoplasm, but also penetrates

\footnotetext{
${ }^{a}$ College of Chemistry, Chemical Engineering and Materials Science, Key Laboratory of Molecular and Nano Probes, Ministry of Education, Shandong Normal University, Jinan 250014, China. E-mail: kangqi@sdnu.edu.cn

${ }^{b}$ CAS Key Laboratory of Coastal Environmental Processes and Ecological Remediation, Research Center for Coastal Environmental Engineering and Technology, Yantai Institute of Coastal Zone Research, Chinese Academy of Sciences, Yantai 264003, China. E-mail: lxchen@yic.ac.cn

${ }^{c}$ College of Chemistry and Chemical Engineering, Qufu Normal University, Qufu 273165, China

$\dagger$ Electronic supplementary information (ESI) available. See DOI: 10.1039/c8tb03054e
}

the nuclear membrane, leading to DNA damage and other physiological changes. ${ }^{4}$ On the other hand, photosensitizers are crucial for PTT which can transform luminous energy to thermal energy under laser irradiation. Tumor cells are more sensitive to temperature than normal cells. Local temperature increase causes DNA damage and apoptosis of tumor cells eventually. ${ }^{5}$ Considering superiority of PDT and PTT, synergetic PDT and PTT therapies have been widely used in clinical treatment of tumor. ${ }^{6-13}$

Recently, design and synthesis of small molecule photosensitizers have been reported. ${ }^{14-16}$ Some fluorescent dyes have demonstrated photosensitization effects, which are closely associated with their lipo-hydro partition coefficients $(\log P)$, polarizabilities, and molar absorption coefficients. ${ }^{17,18}$ Most of the reported photosensitizers with excitation and emission in the visible region are not suitable for imaging and PDT/PTT in deep tissues and organs. ${ }^{19-23}$ Indocyanine green (ICG) is a Food and Drug Administration (FDA)-approved NIR photosensitizer, ${ }^{24,25}$ for clinical use. ${ }^{26}$ However, there are several drawbacks such as self-aggregation in physiological solutions, nonspecific binding to proteins, and rapid renal elimination from the body. To address these problems, researchers developed a new ICG analog, IR-DBI, with simultaneous NIR imaging and chemo/ PDT/PTT/multimodal anticancer activity, which is a better 
treatment than ICG. ${ }^{18}$ However, its maximum absorbance (near $780 \mathrm{~nm}$ ) is far from the wavelength of commonly used $808 \mathrm{~nm}$ excitation laser, thus, affecting the treatment efficacy. Moreover, it is difficult for IR-DBI with a small-molecule structure to accumulate in tumor tissue within suitable treatment time. Therefore, development of an ideal photosensitizer with suitable excitation and emission wavelengths for effective PDT and PTT, which could accumulate in tumor tissue within reasonable time, is necessary.

Photosensitizer loaded, multifunctional nanoplatform generates significant interest is very important for a variety of medical applications. ${ }^{27-32}$ Rapid development of nanomaterials with large surface areas, tunable material properties, and strong signal output will have significant impact on future personalized oncology. ${ }^{33-35}$ Compared with small-molecule photosensitizers, nanoplatform has some advantages, such as superior photostability, effective targeting and long-time accumulation in tumors. ${ }^{36-41}$ To date, various inorganic and organic nanomaterials (NMs), made of carbon, gold and organic polymers, have been utilized in PDT and PTT for cancer treatment. ${ }^{1,35,42-44}$ However, NMs with hydrodynamic diameters ranging from 10 to $200 \mathrm{~nm}$ are susceptible to non-specific accumulation in reticuloendothelial system (RES) organs, which raises concerns about a long-term risk and adverse effects. ${ }^{4-47}$ Recently, protein based theranostics nanoplatforms have been extensively investigated. Self-assembly of amphiphilic photosensitizers and endogenic proteins (such as human serum albumin, HSA) exhibits high drug loading rates, water solubility, biocompatiblity, and tumor selectivity. ${ }^{48-50}$ Moreover, the size (nearly $10 \mathrm{~nm}$ ) is suitable for renal clearance to eliminate possible accumulation and reduce toxicity. ${ }^{48}$

Herein we report the synthesis of a photosensitizer, a benzoheptamethine cyanine dye triphenylphosphonio benzo cyanine (Cy-HPT), with a longer emission wavelength $(860 \mathrm{~nm})$ than previously reported, ${ }^{14}$ which can be beneficial to PDT/PTT in vivo. Furthermore, we synthesized a nanoplatform, HSA@ Cy-HPT, by self-assembling of Cy-HPT and HSA. This nanoplatform exhibits excellent photostability, tumor cell specificity, and satisfactory synergetic PDT/PTT effect in vitro and in vivo via efficient photothermal conversion and generation of ${ }^{1} \mathrm{O}_{2}$ species under NIR laser irradiation. Our study indicates that the synergetic PDT and PTT have the distinguished treatment effect for cancer cells. Western blot analysis verified the HSA@Cy-HPT induced apoptosis by quantifying apoptosis related proteins. In vivo experiments revealed that HSA@Cy-HPT accumulated at the tumor site for a long owing to the EPR effect, followed by efficient renal clearance. Finally, tumor growth was clearly inhibited without any regrowth and an extended survival rate of models treated by the PDT and PTT with HSA@Cy-HPT was observed.

\section{Experimental}

\subsection{Preparation and characterization of HSA@Cy-HPT}

HSA@Cy-HPT was prepared using a method similar to the one previously reported. ${ }^{48}$ Briefly, $5 \mathrm{mg}$ of as-synthesized Cy-HPT was firstly dispersed in $10 \mathrm{~mL}$ methanol. HSA (Sigma-Aldrich, $200 \mathrm{mg}$ ) and $10 \mu \mathrm{L}$ TEA (triethylamine) were mixed in $10 \mathrm{~mL}$ of ultrapure water for $30 \mathrm{~min}$. Then, the mixture was added to $10 \mathrm{~mL}$ of the above-mentioned methanol solution of Cy-HPT for vigorous stirring overnight. After a $24 \mathrm{~h}$ dialysis of the reaction solution with a dialysis bag (MWCO 10 kDa), HSA@Cy-HPT nanoparticles were obtained. The mean particle size was determined by DLS Zetasizer Nano ZS90 (Malvern Instruments Ltd, UK) and TEM (JEOL, model JEM-1230, Japan), operated at $100 \mathrm{kV}$. Optical properties of chemicals and HSA@Cy-HPT nanoparticles were characterized using Thermo Scientific NanoDrop 2000/2000C spectrophotometer and a NIR fluorescence spectrometer (HORIBA Scientific Fluoromax-4 spectro fluorometer with a xenon lamp and $1.0 \mathrm{~cm}$ quartz cell) with $810 \mathrm{~nm}$ excitation and scanning wavelength from $830 \mathrm{~nm}$ to $900 \mathrm{~nm}\left(5 \mathrm{~nm}\right.$ slit width at a scan rate of $\left.600 \mathrm{~nm} \mathrm{~min}^{-1}\right)$.

\subsection{Animals and tumor xenografts}

BALB/c mice (age 5-6 weeks, weight 20-25 g) and athymic nude mice (age 5-6 weeks, weight 20-v25 g) were purchased from Binzhou Medical University. All experimental procedures were conducted in conformity with institutional guidelines for the care and use of laboratory animals, and protocols were approved by the Institutional Animal Care and Use Committee in Binzhou Medical University, Yantai, China. For HepG2 tumor xenografts, $5 \times 10^{6}$ HepG2 cells, suspended in $200 \mu \mathrm{L}$ PBS, were subcutaneously implanted into the right flank of each athymic nude mouse. All animals were maintained under aseptic conditions and housed in a group of five in standard cages with free access to food and water and a $12 \mathrm{~h}$ light/ dark cycle.

\subsection{Tumor NIR fluorescent imaging and thermal imaging}

Animals with HepG2 tumor xenograft models were intravenously injected $10 \mathrm{mg} \mathrm{kg}^{-1}$ HSA@Cy-HPT and used for tumor-targeted NIR imaging with the Perkinelmer IVIS Lumina XRMS Series III In Vivo Imaging System $48 \mathrm{~h}$ after injection. ${ }^{5} \mathrm{NIR}$ imaging of whole animals in vivo was performed at different times $(0.5 \mathrm{~h}, 6 \mathrm{~h}, 24 \mathrm{~h}$, $48 \mathrm{~h}$, and $72 \mathrm{~h}$ ) post drug injection. After sacrificing the mice at $0.5 \mathrm{~h}, 6 \mathrm{~h}, 24 \mathrm{~h}, 48 \mathrm{~h}$ and $72 \mathrm{~h}$, major organs and tumors were dissected for ex vivo NIR fluorescent imaging and to study their tissue distribution. For in vivo assessment of PTT properties, mice with HepG2 tumor xenografts were intravenously injected with $10 \mathrm{mg} \mathrm{kg} \mathrm{kg}^{-1}$ HSA@Cy-HPT. Twenty four $\mathrm{h}$ after injection, realtime temperature change of mice was monitored by the infrared thermal camera (Testo 865, Germany) when the entire tumor tissue was exposed to the continuous NIR laser beam (808 $\mathrm{nm}, 1.5 \mathrm{~W} \mathrm{~cm}^{-2}, 5 \mathrm{~min}$ ). Prior to NIR fluorescence or thermal imaging analysis, mice were anesthetized by inhalation of isoflurane.

\subsection{Synthesis of compound Cy-HPT}

Compound 4 (46.5 mg, $0.05 \mathrm{mmol}$ ) and (4-bromobutyl) triphenylphosphonium bromide $(47.8 \mathrm{mg}, 0.1 \mathrm{mmol})$, were dissolved in dry acetone $(25 \mathrm{~mL})$, then anhydrous potassium carbonate $(27.5 \mathrm{mg}$, $0.2 \mathrm{mmol}$ ) was added. The mixture was stirred under a dry argon 
atmosphere for $24 \mathrm{~h}$ and monitored by TLC. After the reaction was finished, the mixture was cooled to room temperature, dried under reduced pressure and partitioned with $\mathrm{CH}_{2} \mathrm{Cl}_{2}$ and saturated $\mathrm{KBr}$ solution. Finally, the organic layer was separated. Purification by column chromatography on silica eluting with EtOAc/ $\mathrm{CH}_{3} \mathrm{OH}(3: 1)$ yielded the product, Cy-HPT, as dark green crystals $(35.74 \mathrm{mg}, 53 \%) .{ }^{1} \mathrm{H}$ NMR $\left(\mathrm{CH}_{3} \mathrm{DO}, 500 \mathrm{MHz}\right) \delta(\mathrm{ppm})$ : 8.47-8.45 (m, 2H), 7.87-7.76 (m, 6H), 7.63-7.50 (m, 5H), 7.36-7.28 (m, 19H), 7.05-6.91 (m, 5H), 6.37-6.10 (m, 1H), $5.33(\mathrm{~m}, 1 \mathrm{H})$, 4.57-4.27 (m, 2H), 4.13-4.03 (m, 2H), 3.87-3.44 (m, 8H), 3.30 (m, 8H), 2.96-2.93 (m, 1H), 2.63-2.62 (m, 2H), 2.18-2.09 (m, 4H), 1.94-1.88 (m, 8H), 1.76-1.62 (m, 4H), 1.28 (m, 6H), 0.89 (m, 2H). ${ }^{13} \mathrm{C} \mathrm{NMR}\left(\mathrm{CH}_{3} \mathrm{DO}, 125 \mathrm{MHz}\right) \delta(\mathrm{ppm}): 175.7,171.5,165.4,165.1$, 160.6, 137.5, 133.4, 132.0, 131.9, 131.8, 129.8, 129.0, 128.7, 128.6, 128.5, 126.3, 117.3, 113.7, 113.6, 112.4, 112.3, 49.7, 49.6, 49.5, 49.2, 46.7, 46.5, 46.4, 46.2, 46.0, 45.9, 45.7, 45.5, 42.6, 30.1, 27.8, 27.5, 27.4, 25.3, 25.1, 25.0, 24.8, 18.4. LC-MS (ESI $\left.{ }^{+}\right): m / z \mathrm{C}_{88} \mathrm{H}_{86} \mathrm{ClN}_{4} \mathrm{O}_{7} \mathrm{P}^{2+}$ calcd 674.29, found $\left[\mathrm{M}^{+}\right]$674.69.

\section{Results and discussion}

\subsection{Synthesis and characterization of Cy-HPT and HSA@Cy-HPT}

A benzo-heptamethine cyanine dye was designed and synthesized by modification of $N$-alkyl side chains of heptamethine core and named Cy-HPT (Scheme 1). Structures of the Cy-HPT were characterized by ${ }^{1} \mathrm{H} \mathrm{NMR},{ }^{13} \mathrm{C} \mathrm{NMR}$, and mass spectrometry (MS), as described in ESI. $\dagger$ HSA@Cy-HPT nanoparticle (NP) was synthesized by the self-assembly of Cy-HPT and HSA (Scheme 1). Cy-HPT can be adsorbed by the hydrophobic domain of HSA, and this complex with much higher hydrophobicity can act as an "adhesive" between different proteins, inducing assembly of more albumin proteins to form nanoparticles with embedded Cy-HPT. We then carefully characterized the obtained HSA@Cy-HPT nanoparticles. The HSA@Cy-HPT we obtained had the loading ratio of $6.7 \%$ for Cy-HPT. Transmission electron microscopy (TEM) imaging and DLS analysis revealed that the size of NP was around $10 \mathrm{~nm}$, indicating that the Cy-HPT binding dose did not induce severe HSA aggregation (Fig. 1a and b). NPs could be easily dispersed in various physiological buffers. The effect of varying the solution pH on Cy-HPT and HSA@ Cy-HPT was investigated and data are presented in ESI $\dagger$ (Fig. S1).

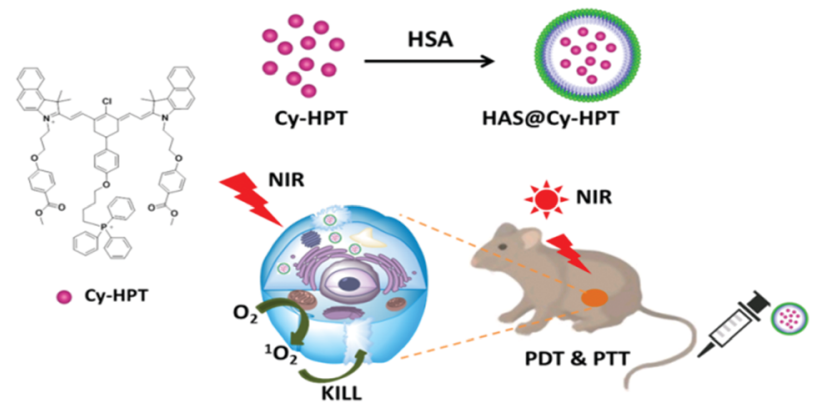

Scheme 1 The synthetic route and the photoinduced treatment mechanism of Cy-HPT and HSA@Cy-HPT.
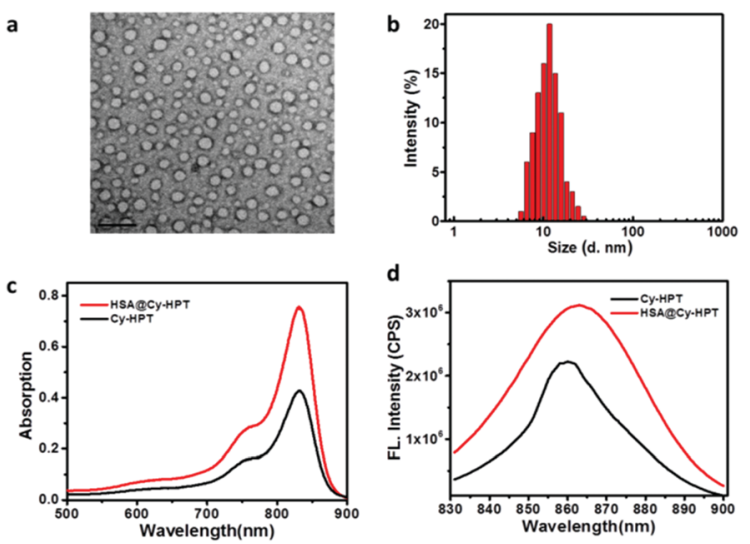

Fig. 1 (a) TEM image of HSA@Cy-HPT. Scale bar: $20 \mathrm{~nm}$. (b) Hydrodynamic diameters of HSACCy-HPT measured by DLS. (c) Absorption spectra of Cy-HPT and HSA@Cy-HPT. (d) Fluorescence emission spectra of Cy-HPT and HSACCy-HPT.

The spectroscopic properties of the Cy-HPT and HSA@Cy-HPT were investigated under simulated physiological conditions (10 mM HEPES pH 7.4). As shown in Fig. 1c, the maximum absorption of Cy-HPT and HSA@Cy-HPT appeared at $830 \mathrm{~nm}$ $\left(\varepsilon_{830 \mathrm{~nm}}=4.2 \times 10^{4} \mathrm{M}^{-1} \mathrm{~cm}^{-1}\right)$ and $833 \mathrm{~nm}\left(\varepsilon_{833 \mathrm{~nm}}=7.9 \times\right.$ $\left.10^{4} \mathrm{M}^{-1} \mathrm{~cm}^{-1}\right)$, respectively. The Cy-HPT and HSA@Cy-HPT exhibited fluorescence emission centered at $860 \mathrm{~nm}$ and $863 \mathrm{~nm}$, respectively, which extended across the NIR region (Fig. 1d). Modification of $\mathrm{N}$-alkyl side chains of heptamethine core might produce long wavelength emission. Because of extremely low tissue autofluorescence and absorption in the NIR spectral range (650-900 $\mathrm{nm}$ ), optical imaging and phototherapy could be realized with high sensitivity and deep tissue penetration. It should be noted that HSA@Cy-HPT exhibited slightly red-shifted absorbance and emission as well as obviously enhanced fluorescence, compared with those of Cy-HPT (Fig. 1d), which likely are due to a slightly changed molecular conformation after Cy-HPT complexed with the albumin protein. If Cy-HPT is adsorbed by the hydrophobic domain of HSA, the complex with much higher hydrophobicity can act as an "adhesive" between different proteins and induce assembly of more albumin proteins to form a nanoparticle, inside which Cy-HPT is embedded. ${ }^{48}$ Satisfactory optical properties lay a foundation for the dyes to be used for bioimaging and tumor treatment.

\subsection{Evaluation of photothermal conversion and singlet oxygen generation efficiency}

Next, we evaluated the photoconverted thermal effects of Cy-HPT and HSA@Cy-HPT in detail. Under exposure to an $808 \mathrm{~nm}$ continuous NIR laser at $1.5 \mathrm{~W} \mathrm{~cm}^{-2}$ for $5 \mathrm{~min}$ (Fig. 2a), the temperature of Cy-HPT (10 $\mu \mathrm{M})$ and HSA@Cy-HPT $\left(200 \mu \mathrm{g} \mathrm{mL}{ }^{-1}\right.$, containing equivalent $10 \mu \mathrm{M}$ of Cy-HPT) solutions rose from $24{ }^{\circ} \mathrm{C}$ to $45{ }^{\circ} \mathrm{C}$ and $55{ }^{\circ} \mathrm{C}$, respectively.

HSA@Cy-HPT exhibited greater photothermal conversion efficiency (54.98\%) than Cy-HPT (45.21\%). There are two explanations for this phenomenon: (1) the absorption coefficient of 

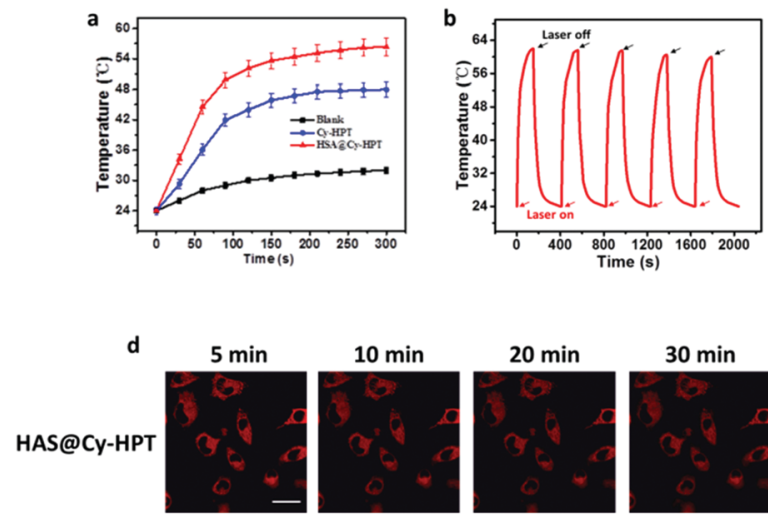

Cy-HPT
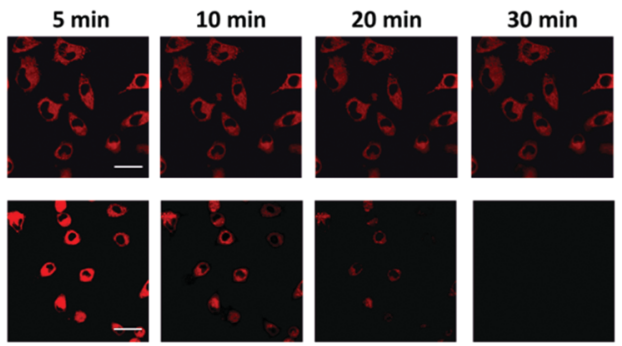
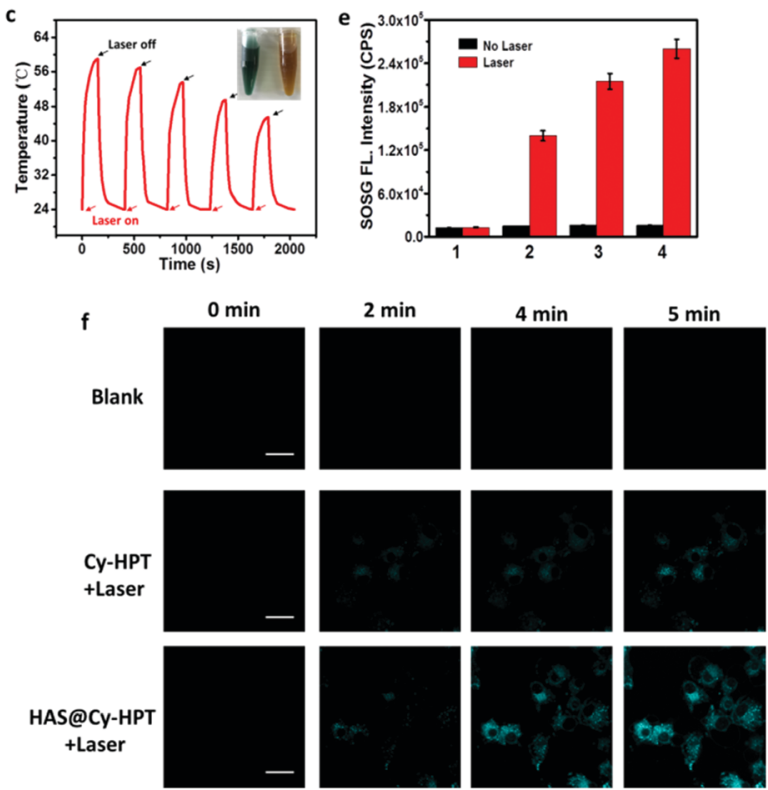

Fig. 2 (a) Temperature dependence curves of Cy-HPT and HSA@Cy-HPT during 5 min NIR laser irradiation. (b) Photothermal stability of HSA@Cy-HPT. (c) Photothermal stability of Cy-HPT. (d) Confocal microscopy images of HepG2 cells showing photothermal stability of Cy-HPT and HSA@Cy-HPT upon continuous laser irradiation for $30 \mathrm{~min}$. Fluorescence channel: $\lambda_{\mathrm{ex}}=808 \mathrm{~nm}, \lambda_{\mathrm{em}}=830-880 \mathrm{~nm}$. (e) Fluorescence intensity of SOSG: (1) blank, (2) ICG, (3) Cy-HPT, and (4) HSA@Cy-HPT. (f) Confocal microscopy images of HepG2 cells for evaluating the generation of ${ }^{1} \mathrm{O}_{2}$ by SOSG upon NIR laser irradiation. Fluorescence channel: $\lambda_{\mathrm{ex}}=490 \mathrm{~nm}, \lambda_{\mathrm{em}}=510-560 \mathrm{~nm}$. Images are representative of $n=5$ independent experiments. Scale bar $=20 \mu \mathrm{m}$.

HSA@Cy-HPT is 42\% higher than that of Cy-HPT because of the complex formation and (2) photostability of HSA@Cy-HPT is dramatically increased. It has been reported that ICG decomposition is due to a break of the double bonds under irradiation; ${ }^{51}$ such phenomenon also occurred with Cy-HРT in our study. As shown in Fig. 2c, the color of Cy-HPT sample disappeared after five cycles of irradiation at $808 \mathrm{~nm}, 1.5 \mathrm{~W} \mathrm{~cm} \mathrm{~cm}^{-2}$ for $10 \mathrm{~min}$, owing to a similar double-bond breaking decomposition mechanism, proved by analyzing mass spectra of the sample solution $(\mathrm{m} / \mathrm{z}=403.46,429.73$ and 964.44) and characterizing the structures of the decomposition products (Fig. S1, ESI $\dagger$ ). Cy-HPT was decomposed by laser via a reaction of the double bonds of the flexible polymethine chain with photo-induced generated ${ }^{1} \mathrm{O}_{2}$ by cycloaddition, followed by thermal decomposition into carbonyl compounds. $^{52,53}$ By contrast, as shown in Fig. $2 \mathrm{~b}$ and c, heat stability of HSA@Cy-HPT greatly increased, because the molecular conformation of Cy-HPT, embedded in the hydrophobic region of HSA, was stabilized, preventing the occurrence of oxidationinduced decomposition reaction. Thus, photo-stability and photothermal characteristics of Cy-HPT in hybrid NPs dramatically improved.

Similar results were be obtained in living cells. As shown in Fig. 2d, the fluorescence signal of HSA@Cy-HPT in HepG2 cells exhibited stability after laser irradiation for $30 \mathrm{~min}$. By contrast, fluorescence of Cy-HPT labeled cells visibly decreased within $10 \mathrm{~min}$ and totally disappeared after a $30 \mathrm{~min}$ irradiation. This result suggested that HSA@Cy-HPT was suitable for long-term repeated cancer treatment.

Furthermore, singlet oxygen $\left({ }^{1} \mathrm{O}_{2}\right)$ species, generated from Cy-HPT and HSA@Cy-HPT, were also detected by using Singlet oxygen sensor green (SOSG, Invitrogen co., USA) as a probe.
As shown in Fig. 2e, emission intensity indicated that ${ }^{1} \mathrm{O}_{2}$ was generated by Cy-HPT and HSA@Cy-HPT in solution. However, ${ }^{1} \mathrm{O}_{2}$ production of HSA@Cy-HPT was higher than that of both Cy-HPT and blank water. We also compared ${ }^{1} \mathrm{O}_{2}$ generation of Cy-HPT and HSA@Cy-HPT with that of indocyanine green (ICG), which is a nontargeting clinically available heptamethine cyanine dye. ${ }^{54}$ As shown in Fig. 2e, Cy-HPT and HSA@Cy-HPT produced more ${ }^{1} \mathrm{O}_{2}$ than ICG. This finding is consistent with previous studies. ${ }^{16} \mathrm{Next},{ }^{1} \mathrm{O}_{2}$ generation of Cy-HPT and HSA@Cy-HPT in cells upon NIR laser irradiation was investigated. SOSG was employed to detect generation of ${ }^{1} \mathrm{O}_{2}$ in living cells using laser scanning confocal microscope. As shown in Fig. 2f, the control group exhibited weak fluorescence, indicating lack of ${ }^{1} \mathrm{O}_{2}$ in blank cells. Both groups exhibited fluorescence with prolonged irradiation time and the signal from HSA@Cy-HPT treated cells was stronger. These imaging results confirmed that HSA@Cy-HPT could generate more ${ }^{1} \mathrm{O}_{2}$ in living cells under laser irradiation. The above results show the potential of Cy-HPT and HSA@Cy-HPT for PDT/PTT therapy.

\subsection{In vitro photoinduced cytotoxicity and organelle localization}

Next, we tested the in vitro ability of Cy-HPT and HSA@Cy-HPT to kill cancer cells. HepG2 cells, originally obtained from the Committee on Type Culture Collection of Chinese Academy of Sciences (Shanghai, China) and cultured under recommended conditions, were incubated with free Cy-HPT and HSA@Cy-HPT for $72 \mathrm{~h}$. The standard cell viability assay using 3-(4,5-dimethylthiazol-2yl)-2,5-diphenyltetrazolium bromide (MTT) was then conducted. As demonstrated in Fig. 3a and b, above 72\% (Cy HPT) and 81\% (HSA@Cy-HPT) of cells survived for tumor cells (HepG2 cells) 

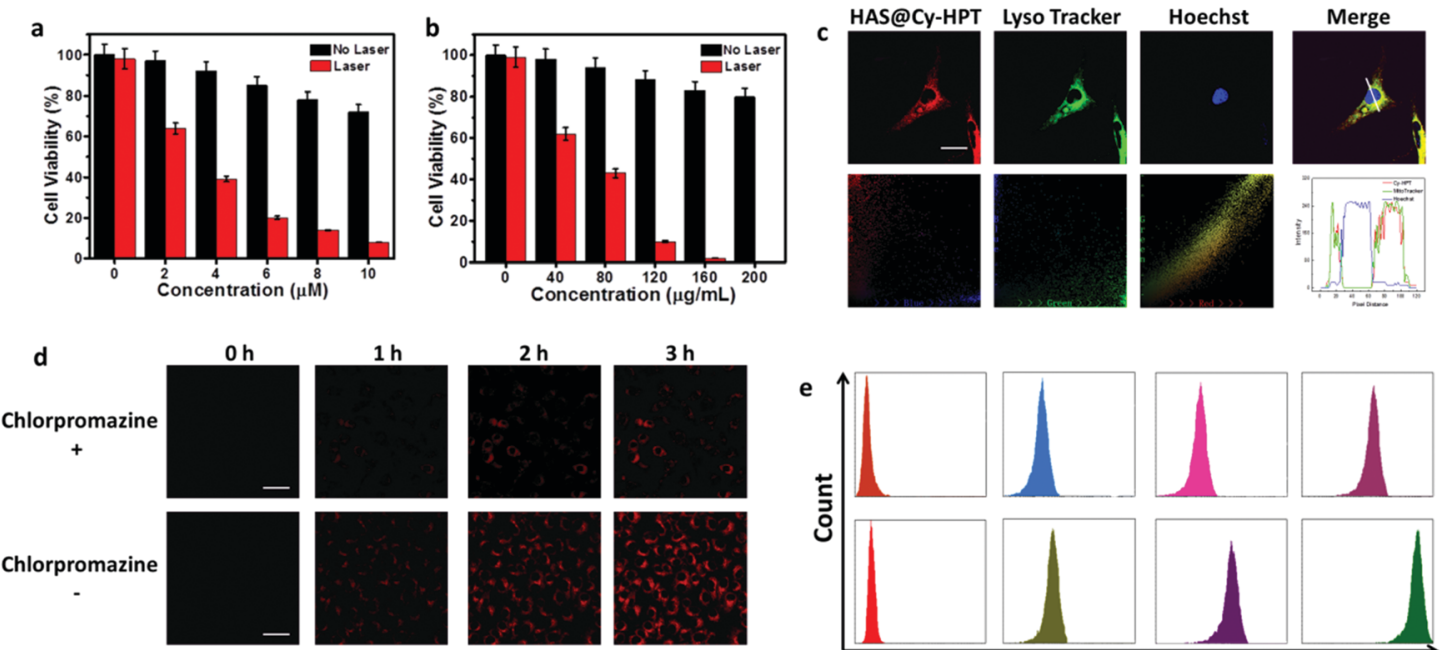

Chlorpromazine
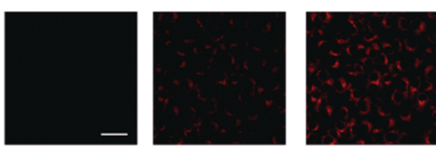

西

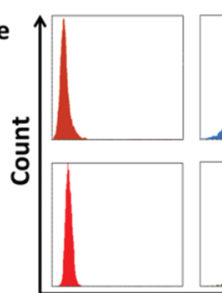

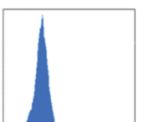
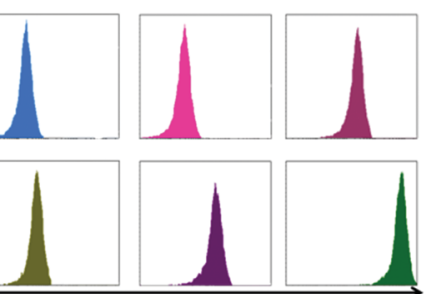

F.L. Intensity

Fig. 3 Cytotoxicity of (a) Cy-HPT and (b) HSACCy-HPT in HepG2 cells with and without laser irradiation. (c) Lysosome localization of HSA@Cy-HPT was determined by co-staining HSA@Cy-HPT with lysosome tracker (Lyso Tracker) in HepG2 cells. Co-localization areas of red and blue channels were selected, co-localization areas of the green and blue channels were selected, co-localization areas of the green and red channels were selected and the intensity profiles of regions of interest (white line in Merge) across cells were measured. Red channel: $\left(\lambda_{\mathrm{ex}}=808 \mathrm{~nm}, \lambda_{\mathrm{em}}=830-880 \mathrm{~nm}\right)$. Lyso Tracker showing lysosomes (green channel: $\lambda_{\mathrm{ex}}=559 \mathrm{~nm}, \lambda_{\mathrm{em}}=570-650 \mathrm{~nm}$ ). Hoechst showing nuclei (blue channel: $\lambda_{\mathrm{ex}}=405 \mathrm{~nm}, \lambda_{\mathrm{em}}=425-525 \mathrm{~nm}$ ). Images are representative of $n=5$ independent experiments. Scale bar: $10 \mu \mathrm{m}$. (d) Confocal microscopy images of HepG2 cells showing cellular uptake of HSA@Cy-HPT via endocytosis. Scale bar: $40 \mu \mathrm{m}$. (e) Flow cytometry assay of HepG2 cells corresponding to (d).

after the cells were incubated with $10 \mu \mathrm{M}$ Cy HPT or $200 \mu \mathrm{g} \mathrm{mL}$ HSA@Cy-HPT for $72 \mathrm{~h}$, then the 50\% cell survival concentration value $\left(\mathrm{IC}_{50}\right.$ ) was predicted to be $32 \mu \mathrm{M}$ (Cy-HPT) and $826 \mu \mathrm{g} \mathrm{mL}$ (HSA@Cy-HPT) for HepG2 cells, respectively, which indicated the low cytotoxicity of Cy-HPT and HSA@Cy-HPT under no laser irradiation.

On the basis of the above experiments, it was necessary to verify whether Cy-HPT and HSA@Cy-HPT could produce a phototherapeutic effect in complex biological systems. First, we tested Cy-HPT and HSA@Cy-HPT for their PTT and PDT ability in tumor cells (HepG2 cells). MTT assay showed that cell viability in the radiation groups decreased with the increased concentration of Cy-HPT $(0-10 \mu \mathrm{M})$ and HSA@Cy-HPT $\left(0-200 \mu \mathrm{g} \mathrm{mL}{ }^{-1}\right)$. Also, the cell viability rate obviously decrease at $10 \mu \mathrm{M}$ (Сy-HPT) and $200 \mu \mathrm{g} \mathrm{mL}^{-1}$ (HSA@Cy-HPT) (Fig. 3a and b). In contrast, cell viability in groups with no laser treatment was not affected significantly. These data demonstrate that Cy-HPT and HSA@Cy-HPT were able to kill tumor cells when combined with PTT and PDT.

Nanoparticles can selectively enter cancer cells via endocytosis of lysosomes. ${ }^{55}$ Therefore, organelle co-localization of HSA@Cy-HPT was investigated. As shown in Fig. 3c, HepG2 cells were able to uptake HSA@Cy-HPT after a $3 \mathrm{~h}$ incubation. A large amount of HSA@Cy-HPT accumulated and colocalized with LysoTracker in the cells, indicating that the HSA@Cy-HPT could be taken up by cancer cells via endocytosis. Afterward, endocytosis was further studied using an inhibitor. Chlorpromazine, an inhibitor of clathrin-mediated endocytosis, ${ }^{15}$ was employed in HepG2 cells experiment. HepG2 cells were treated with chlorpromazine $\left(15 \mu \mathrm{g} \mathrm{mL}^{-1}\right)$ for $1 \mathrm{~h}$, then HSA@Cy-HPT, as described in above experiment, was added to the cells for $3 \mathrm{~h}$. As shown as Fig. 3d, faint fluorescence was exhibited by cells, and $\approx 40 \%$ decrease in cellular uptake of HSA@Cy-HPT indicated that nanoparticles were mainly internalized via endocytosis.

\subsection{Cellular uptake kinetics and cellular selectivity}

On the basis of the above fluorescence imaging experiments, cellular uptake of Cy-HPT and HSA@Cy-HPT was studied. By choosing HepG2 cells as models, the cells were treated with Cy-HPT (2 $\mu \mathrm{M})$ and HSA@Cy-HPT (40 $\mu \mathrm{g} \mathrm{mL} \mathrm{m}^{-1}$, containing equivalent $2 \mu \mathrm{M}$ of Cy-HPT), then subjected to cell fluorescence imaging by a laser scanning confocal microscope at different time points. As shown in Fig. 4a, cells were treated with Cy-HPT and HSA@Cy-HPT for $0-3 \mathrm{~h}$ and the fluorescence signal became stronger over time, indicating that cellular uptake of Cy-HPT and HSA@Cy-HPT was time-dependent. However, when cells were treated with HSA@Cy-HPT for $3 \mathrm{~h}$ and Cy-HPT for $0.5 \mathrm{~h}$, the fluorescence signal reached its maximum value. This result demonstrates that Cy-HPT and HSA@Cy-HPT had the most intracellular accumulation after that treated for $0.5 \mathrm{~h}$ and $3 \mathrm{~h}$, respectively. This is beneficial to determine the optimal time of PDT and PTT in the tumor cells.

It has been reported that HSA NPs possess both passive and active tumor-targeting abilities via enhanced permeability and retention (EPR) effect and gp60 and SPARC receptor-mediated transcytosis. $^{26}$ In our study, cellular uptake selectivity of the nanoparticles HSA@Cy-HPT was examined. HSA@Cy-HPT was added to both tumor cells (HepG2 cells) and normal cells (L02 cells) at $37{ }^{\circ} \mathrm{C}$ for a $3 \mathrm{~h}$ incubation. As shown in Fig. $4 \mathrm{~b}$, only a weak fluorescence signal was observed in L02 cells after a $3 \mathrm{~h}$ incubation. The obvious difference in fluorescence 

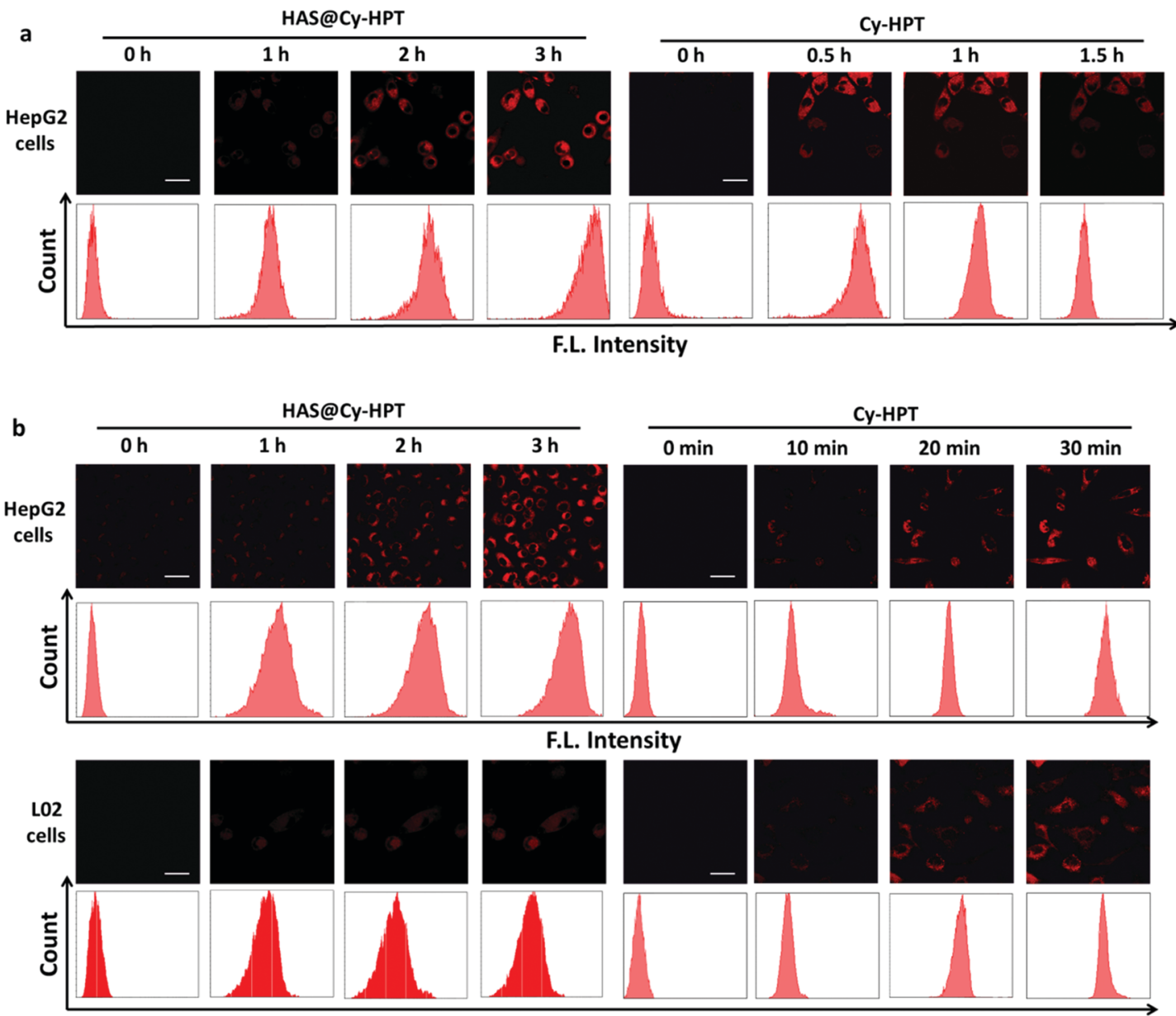

F.L. Intensity

Fig. 4 (a) Confocal microscopy images and flow cytometry assay of HepG2 cells for the kinetics experiment of Cy-HPT and HSA@Cy-HPT cellular uptake. (b) Selective cellular uptake of HSA@Cy-HPT and free Cy-HPT by tumor cells (HepG2 cells) and normal cells (L02 cells). Fluorescence channel: $\lambda_{\mathrm{ex}}=808 \mathrm{~nm}, \lambda_{\mathrm{em}}=830-880 \mathrm{~nm}$. Images are representative of $n=5$ independent experiments. Scale bar $=20 \mu \mathrm{m}$.

intensities between cancer cells and normal cells suggested the cancer targeting capability of HSA@Cy-HPT. For comparison, the same experiment was performed with $2 \mu \mathrm{M}$ of free Cy-HPT. There were no obvious differences between tumor cells and normal cells (Fig. 4b), probably owing to small molecules entering cells mainly via non-specific free diffusion. The enhanced endocytosis of HSA@Cy-HPT by tumor cells was also verified by flow cytometry. The results were consistent with those of cell fluorescence imaging experiments. These results indicated that HSA@Cy-HPT nanoparticles had tumor targeting capability without any tumor targeting ligands, and an enhanced uptake of HSA@Cy-HPT due to gp60 and SPARC receptormediated transcytosis was observed. ${ }^{26}$ This is beneficial to obtaining ideal curative effect for real tumor treatment applications.

\subsection{In vitro synergetic PDT, PTT effect of HSA@Cy-HPT}

To verify that synergetic PDT and PTT treatments contributed to the therapeutic effect of HSA@Cy-HPT, laser irradiation of HepG2 cells was performed with ice incubation for a single PDT treatment. Alternatively, cells were pretreated with $\mathrm{N}$-acetylcysteine (NAC) and $\mathrm{NaN}_{3}$ to scavenge ROS and $\mathrm{O}_{2}{ }^{56}$ for a single
PTT treatment. When cells were treated with HSA@Cy-HPT at $0 \mu \mathrm{g} \mathrm{mL}{ }^{-1}, 40 \mu \mathrm{g} \mathrm{mL}{ }^{-1}, 80 \mu \mathrm{g} \mathrm{mL}^{-1}, 120 \mu \mathrm{g} \mathrm{mL}^{-1}, 160 \mu \mathrm{g} \mathrm{mL}^{-1}$, and $200 \mu \mathrm{g} \mathrm{mL} \mathrm{m}^{-1}$, MTT assay showed that no cell viability was detected in both PTT and PDT treatment groups at $200 \mu \mathrm{g} \mathrm{mL}^{-1}$ (HSA@Cy-HPT), 20.3\% cell viability was detected with PTT treatment alone, and $12.4 \%$ cell viability was detected with PDT treatment alone (Fig. 5a). These results suggest that the photoinduced cytotoxicity of HSA@Cy-HPT is synergistically enhanced by PDT and PTT combinatorial treatment and the treatment effect of HSA@Cy-HPT for tumor cells is effective. The phototoxicity of HSA@Cy-HPT was also confirmed by fluorescence images of Calcine AM and propidium iodide (PI) co-stained HepG2 cells (Fig. 5b). The green fluorescence of Calcine AM and the red fluorescence of PI corresponded to the live and dead cells, respectively, confirming the synergistic effects of PDT and PTT. Flow cytometry with Annexin V-PE was performed to evaluate the apoptosis rate of cells with PTT alone, PDT alone and synergetic effect of PDT and PTT. After a $3 \mathrm{~h}$ incubation with $200 \mu \mathrm{g} \mathrm{mL}{ }^{-1}$ HSA@Cy-HPT and 5 min NIR light irradiation $\left(808 \mathrm{~nm}, 1.5 \mathrm{~W} \mathrm{~cm} \mathrm{~cm}^{-2}\right)$, apoptotic ratios of synergetic PDT and PTT were observed with obvious increase 
a

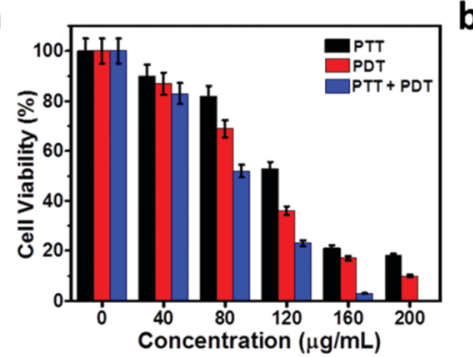

C

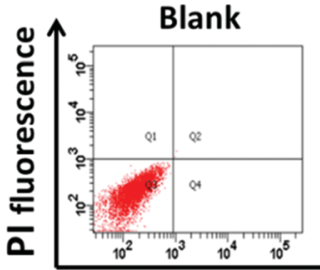

b

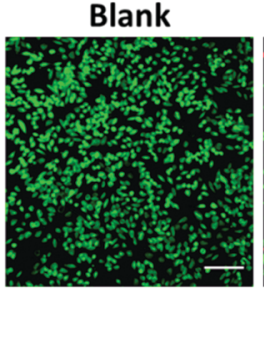

PTT

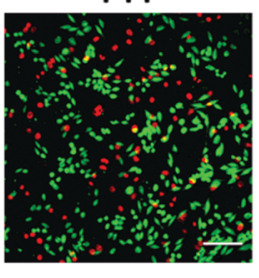

PDT

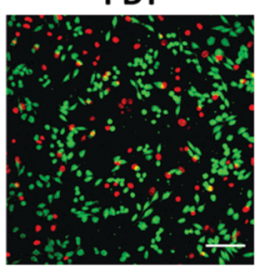

PTT+PDT

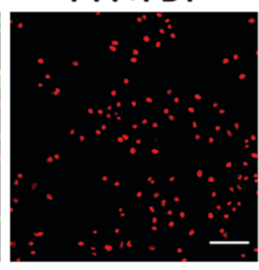

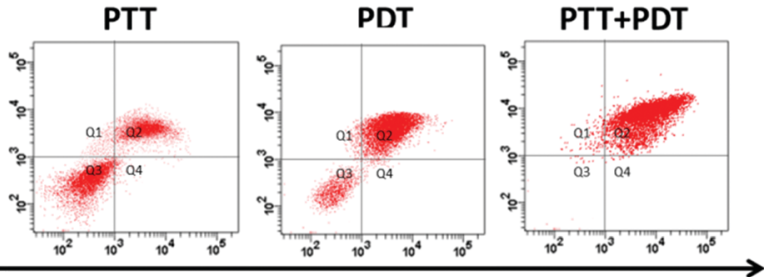

Annexin V fluorescence

Fig. 5 (a) MTT assay results of PTT, PDT and synergetic PDT and PTT treatments with HSACCy-HPT in HepG2 cells. (b) Fluorescent images of Calcein AM/PI co-stained HepG2 cells after PTT, PDT, or synergetic PDT and PTT treatments with HSA@Cy-HPT. Scale bar: $60 \mu \mathrm{m}$. (c) Flow cytometry analysis of Annexin V-PE to evaluate the apoptosis rate of PTT, PDT and synergetic PDT and PTT treatments. (d) Western blot analysis of Hsp70 after PTT, PDT and synergetic PDT and PTT treatmnets; $\beta$-actin was used as a loading control.

a
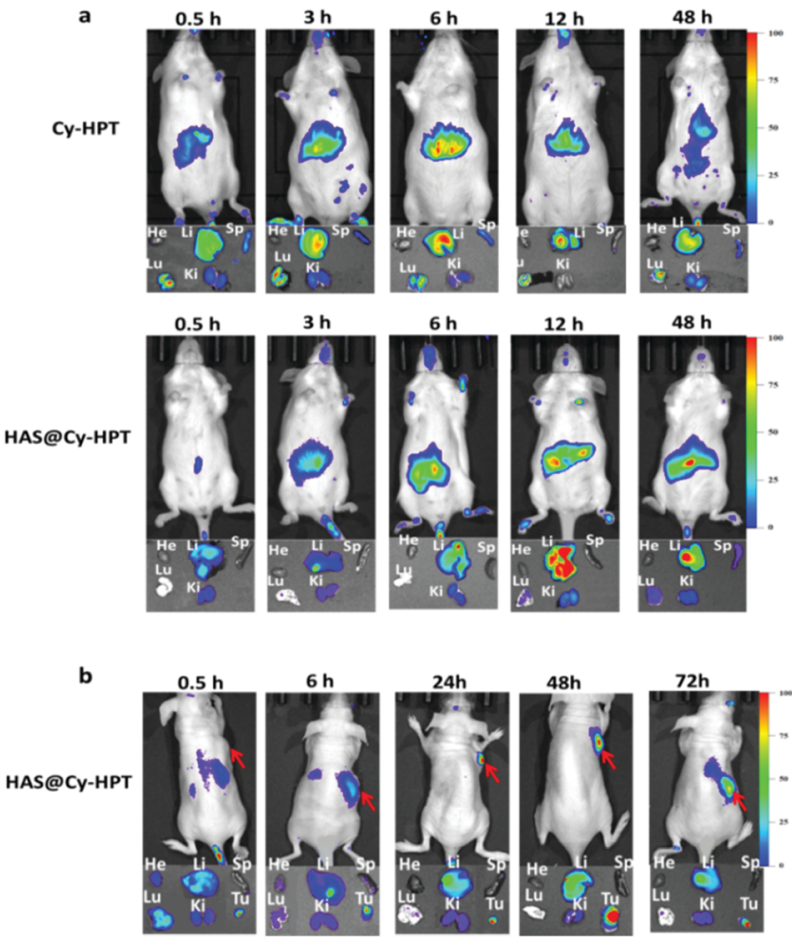

Fig. 6 (a) Fluorescence imaging in BALB/c mice injected with Cy-HPT and HSA@Cy-HPT and ex vivo fluorescent imaging of dissected main organs at different time points. (b) Fluorescence imaging in subcutaneous HepG2 tumor models injected with HSA@Cy-HPT and ex vivo fluorescent imaging of dissected main organs at different time points. He: heart; Li: liver; Sp: spleen; Lu: lung; Ki: kidney; Tu: tumor. Images represent emission intensity collection window: $830-880 \mathrm{~nm}, \lambda_{\mathrm{ex}}=808 \mathrm{~nm}$. Data are presented as mean $\pm \mathrm{SD}(n=5)$

than the single PTT or single PDT for HepG2 cells (Fig. 5c). Therefore, cell death was mediated by the synergetic PDT and
PTT treatment with HSA@Cy-HPT. Heat shock protein 70 (Hsp70) is typically synthesized in response to heat stress to protect the cell from thermal or oxidative stress. ${ }^{57}$ Thus, Hsp70 expression was monitored to evaluate heat stress of cells. As shown in Fig. 5d, Hsp70 expression was significantly increased following PTT and synergetic PDT and PTT treatments, further indicating that cell apoptosis was mediated by the synergetic PDT and PTT effect of HSA@Cy-HPT.

\subsection{In vivo NIR fluorescent imaging and tumor-bearing mice imaging}

HSA@Cy-HPT was chosen as an ideal PDT and PTT agent used in mice and tumor xenograft models owing to its excellent photothermal conversion ability and photodynamic properties. First, application of HSA@Cy-HPT for fluorescence imaging in vivo was studied in BALB/c mice. Simultaneously, pharmacokinetics of HSA@Cy-HPT in vivo was investigated also, using Cy-HPT as the control. All experimental procedures were conducted in conformity with institutional guidelines for the care and use of laboratory animals, and protocols were approved by the Institutional Animal Care and Use Committee in Binzhou Medical University, Yantai, China (Approval Number: No. BZ2014-102R). HSA@Cy-HPT (10 mg kg $\left.{ }^{-1}\right)$ and Cy-HPT $\left(5 \mathrm{mg} \mathrm{kg}^{-1}\right.$ ) were injected into BALB/c mice by intravenous (IV) injection. NIR fluorescent imaging was performed at different time points. As shown as Fig. 6a, a weak fluorescence signal was obtained in the beginning, then the fluorescence signal was becoming stronger and stronger with time. The strongest fluorescence signal (mainly in the liver) was obtained $12 \mathrm{~h}$ after HSA@Cy-HPT was injected and $6 \mathrm{~h}$ after Cy-HPT was injected. Then, the fluorescence signal weakened owing to the mice metabolism. Next, the main tissues and organs were removed by dissecting, the fluorescence signal of ex vivo organs 
(heart, liver, spleen, lung, kidney) were analyzed by fluorescence imaging. High contrast in fluorescence between liver and other normal tissue in BALB/c mice was observed, suggesting preferential accumulation of HSA@Cy-HPT in the liver as a major metabolic site. Also, fluorescence signal was obtained in kidneys. These results revealed that HSA@Cy-HPT nanoparticles not only remained in vivo longer than free Cy-HPT, but also exhibited an efficient renal clearance to avoid the longterm risk of adverse effects.

Nanoparticles that can preferentially accumulate at the tumor site via enhanced permeability and retention (EPR) without requiring chemical conjugation of tumor-targeting ligands have been recently identified and have shown unique properties for in vivo cancer imaging. ${ }^{46,58}$ In order to evaluate cancer cell specificity of HSA@Cy-HPT, nude mice bearing HepG2 cell xenografts were utilized as described previously. HSA@Cy-HPT $\left(10 \mathrm{mg} \mathrm{kg}^{-1}\right.$ ) was injected intravenously into nude mice bearing HepG2 cell tumor xenografts and then NIR fluorescent imaging was performed using Perkinelmer IVIS Lumina XRMS Series III In Vivo Imaging System. As shown in Fig. 6b, the fluorescence signal appeared in the liver $0.5 \mathrm{~h}$ after intravenous injection. Six hours after HSA@Cy-HPT was injected after, a strong fluorescence signal was obtained in the tumor tissue site. As expected, the fluorescence signal of tumor site was continuous, and an

a

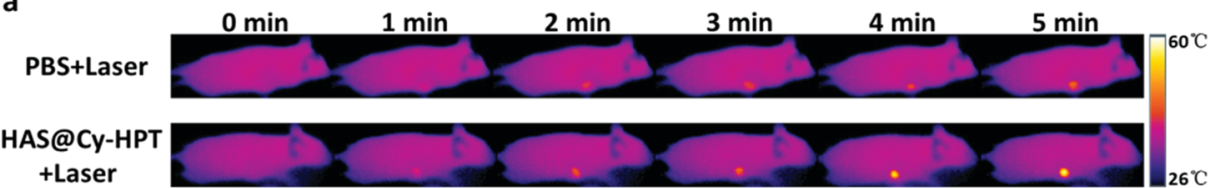

b

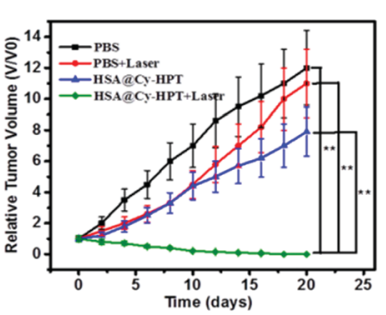

PBS

e

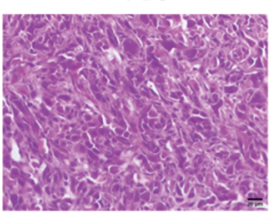

C
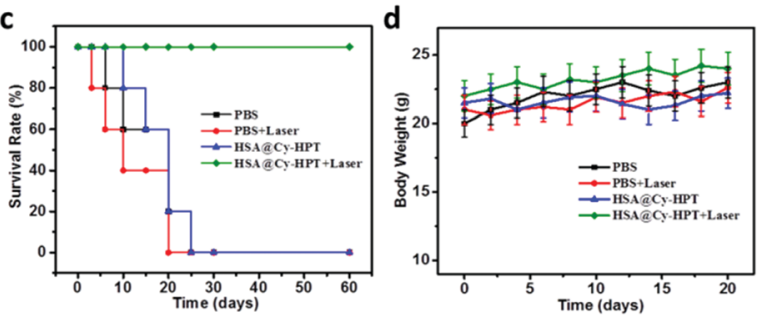

PBS+Laser
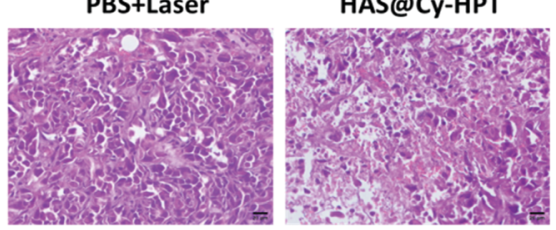

HAS@Cy-HPT+Laser

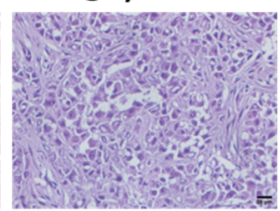

f

\section{Heart}

PBS
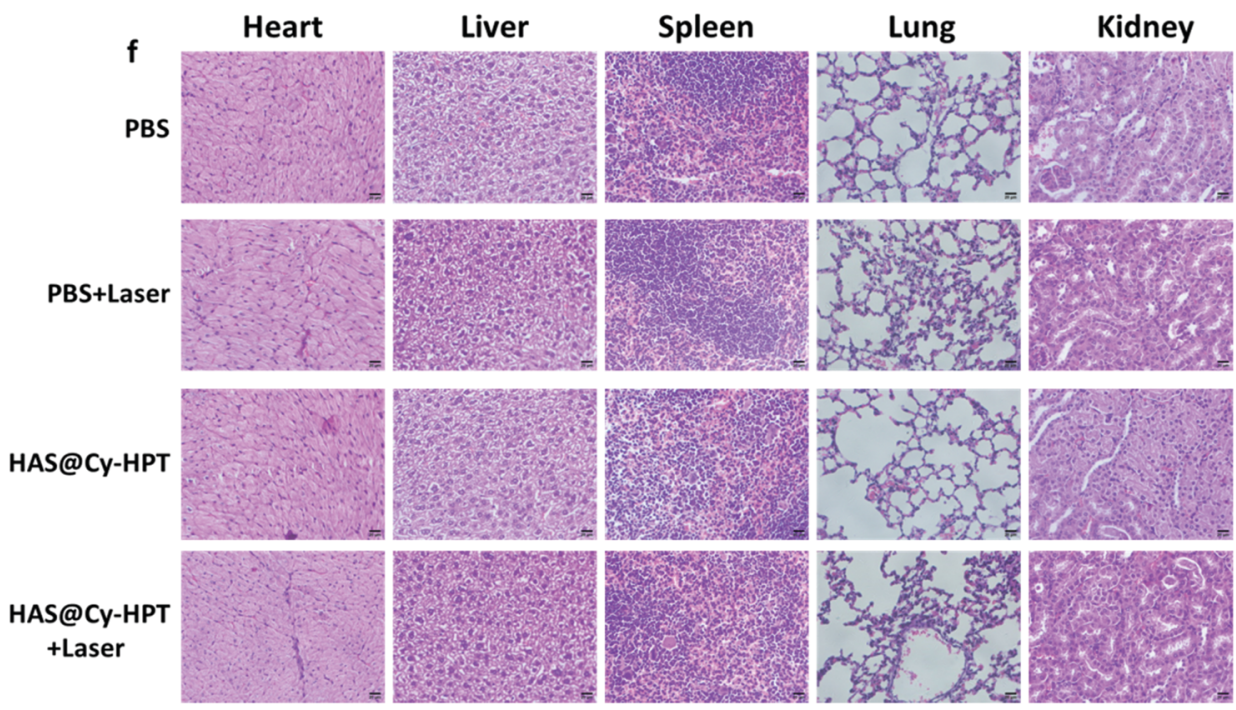

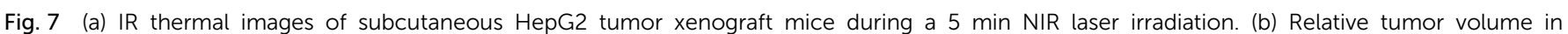

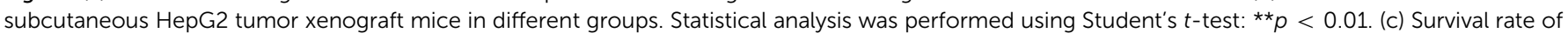

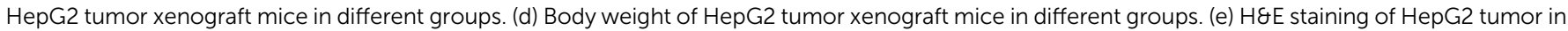

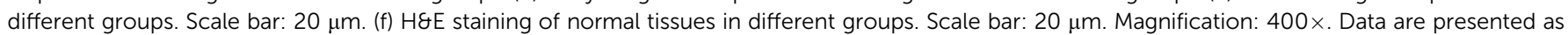
mean $\pm \mathrm{SD}(n=5)$. 
effective fluorescence signal still existed $72 \mathrm{~h}$ later. To further confirm accumulation of HSA@Cy-HPT in tumor tissue site, mice were sacrificed and their main organs containing tumors were dissected. The ex vivo NIR imaging of the dissected organs from above models further confirmed their preferential accumulation in tumors (Fig. 6b). These results demonstrated that HSA@Cy-HPT was an effective nano-reagent for tumor-targeted in vivo intervention and long-time accumulation of HSA@CyHPT at the tumor site was beneficial for efficient PDT and PTT.

\subsection{Thermal imaging and phototherapy in xenograft model}

On the basis of the above experiments, in vivo phototherapeutic efficacy of HSA@Cy-HPT initially elucidated in HepG2 subcutaneous tumor xenograft models. Tumor xenograft models were divided into four groups. PBS buffer solution was into the tumor xenograft models by intravenous injection as PBS nonirradiation group, the tumor xenograft models were injected PBS and exposure to an $808 \mathrm{~nm}$ continuous NIR laser at $1.5 \mathrm{~W} \mathrm{~cm}^{-2}$ for $5 \mathrm{~min}$ at $24 \mathrm{~h}$ postinjection as PBS irradiation group, the tumor xenograft models were injected HSA@Cy-HPT (10 $\mathrm{mg} \mathrm{kg}^{-1}$ ) as HSA@Cy-HPT nonirradiation group, the tumor xenograft models were injected HSA@Cy-HPT and exposure to an $808 \mathrm{~nm}$ continuous NIR laser at $1.5 \mathrm{~W} \mathrm{~cm}^{-2}$ for $5 \mathrm{~min}$ at $24 \mathrm{~h}$ postinjection as HSA@Cy-HPT irradiation group. Then tumor xenograft models were thermal imaged by Infrared Thermal Camera (TESTO 865) to monitor the real-time surface temperature of tumors $24 \mathrm{~h}$ after injection. As shown in Fig. 7a, the temperature of PBS irradiation group increased to $43{ }^{\circ} \mathrm{C}$ after 5 min irradiation. As expected, the temperature of HSA@Cy-HPT irradiation group reached almost $60{ }^{\circ} \mathrm{C}$ after a 5 min irradiation, which was high enough to ablate tumors. ${ }^{59}$ Therefore, HSA@ Cy-HPT has a huge potential as a nano-reagent for efficient PTT therapy in tumor xenograft models.

To evaluate the inhibitory effect of HSA@Cy-HPT on tumor growth in tumor xenograft models, the relative tumor volumes were recorded for $20 \mathrm{~d}$ after treatment. PBS nonirradiation group and PBS irradiation group showed a $\approx 12$-fold increase in tumor volumes, suggesting that irradiation at $808 \mathrm{~nm}$ has no influence on tumor growth (Fig. 7b). And HSA@Cy-HPT nonirradiation group also exhibited similar tumor growth in the absence of $808 \mathrm{~nm}$ irradiation, owing to its negligible cytotoxicity. Importantly, the HSA@Cy-HPT irradiation group demonstrated an obvious tumor ablation without any regrowth under $808 \mathrm{~nm}$ irradiation (Fig. 7b). In addition, the survival rate was recorded for $60 \mathrm{~d}$ after treatment. The survival rate of HSA@Cy-HPT irradiation group remained at $100 \%$. This result demonstrated that HSA@ Cy-HPT offers excellent PDT/PTT tumor growth inhibition effect and improves the survival rate of cells.

To verify the anticancer efficacy of HSA@Cy-HPT under $808 \mathrm{~nm}$ laser irradiation, we further examined its tumordamaging ability using body weight of tumor xenograft models, as well as the hematoxylin \& eosin (H\&E) staining of tumor and healthy tissues. Body weight slightly decreased in PBS irradiation groups in the first several days and no significant difference for all groups at the end of observation period (Fig. 7d) was detected, suggesting tolerance to this treatment and its insignificant photoinduced side effects. For H\&E staining, HSA@Cy-HPT irradiation group demonstrated destructive cell necrosis in the tumor $6 \mathrm{~h}$ after irradiation (Fig. 7e), indicating severe cell injury. By contrast, PBS nonirradiation group, PBS irradiation group and HSA@Cy-HPT nonirradiation group had no distinct tumor damage regardless of irradiation time. Moreover, HSA@Cy-HPT caused no distinct damage to normal tissue such as heart, liver, spleen, lung and kidney (Fig. 7f). Hence, it is clear that HSA@Cy-HPT can precisely induce potent photothermal damage to the tumors, synergized with photodynamic damage under $808 \mathrm{~nm}$ irradiation.

\section{Conclusions}

In summary, we have developed a small molecule fluorophore Cy-HPT as a photosensitizer and a nanoparticle HSA@Cy-HPT as a tumor-targeted nano-photosensitive material. Cy-HPT and HSA@Cy-HPT exhibited excellent PDT/PTT effect in vitro and in vivo and were metabolized in living mice within reasonable time. However, photothermal stability, photothermal conversion and generation of ${ }^{1} \mathrm{O}_{2}$ species by HSA@Cy-HPT were better than those free Cy-HPT, and HSA@Cy-HPT was accumulated at the tumor site for a long time. These results suggest that HSA@Cy-HPT could serve as a tumor-targeting NIR imaging reagent in vivo for precise surgical intervention. In addition, our formulated HSA@Cy-HPT was effectively combined with PDT and PTT under the guidance of NIR imaging. Such treatment approach not only resulted in obvious tumor ablation without any regrowth and extended survival rate of mice, but also offered significant therapeutic benefit by exhibiting its minimal side effects in our study. We hope that with the help of this biocompatible theranostic agent, imaging-guided combined PDT and PTT treatment would bring new perspective to the future fight against cancer.

\section{Conflicts of interest}

There are no conflicts to declare.

\section{Acknowledgements}

We thank the National Nature Science Foundation of China (No. 21575159, 81573393, 21575080), the program of Youth Innovation Promotion Association, CAS (Grant 2017256), and the Instrument Developing Project of the Chinese Academy of Sciences (YZ201662).

\section{References}

1 L. Cheng, C. Wang, L. Feng, K. Yang and Z. Liu, Chem. Rev., 2014, 114, 10869-10939.

2 D. Jaque, M. L. Martinez, R. B. Del, P. Haro-Gonzalez, A. Benayas, J. L. Plaza, R. E. Martin and S. J. Garcia, Nanoscale, 2014, 6, 9494-9530. 
3 D. E. Dolmans, D. Fukumura and R. K. Jain, Nat. Rev. Cancer, 2003, 3, 380-387.

4 P. Agostinis, K. Berg, K. A. Cengel, T. H. Foster, A. W. Girotti, S. O. Gollnick, S. M. Hahn, M. R. Hamblin, A. Juzeniene, D. Kessel, M. Korbelik, J. Moan, P. Mroz, D. Nowis, J. Piette, B. C. Wilson and J. Golab, Ca-Cancer J. Clin., 2011, 61, 250-281.

5 I. Hilger, A. Rapp, K. O. Greulich and W. A. Kaiser, Radiology, 2005, 237, 500-506.

6 Y. Du, Q. Jiang, N. Beziere, L. Song, Q. Zhang, D. Peng, C. Chi, X. Yang, H. Guo, G. Diot, V. Ntziachristos, B. Ding and J. Tian, Adv. Mater., 2016, 28, 10000-10007.

7 S. Wang, X. Li, Y. Chen, X. Cai, H. Yao, W. Gao, Y. Zheng, X. An, J. Shi and H. Chen, Adv. Mater., 2015, 27, 2775-2782.

8 M. Zheng, C. Yue, Y. Ma, P. Gong, P. Zhao, C. Zheng, Z. Sheng, P. Zhang, Z. Wang and L. Cai, ACS Nano, 2013, 7, 2056-2067.

9 H. J. Mauceri, N. N. Hanna, M. A. Beckett, D. H. Gorski, M. J. Staba, K. A. Stellato, K. Bigelow, R. Heimann, S. Gately, M. Dhanabal, G. A. Soff, V. P. Sukhatme, D. W. Kufe and R. R. Weichselbaum, Nature, 1998, 394, 287-291.

10 W. Zhang, Z. Guo, D. Huang, Z. Liu, X. Guo and H. Zhong, Biomaterials, 2011, 32, 8555-8561.

11 H. Park, J. Yang, J. Lee, S. Haam, I. H. Choi and K. H. Yoo, ACS Nano, 2009, 3, 2919-2926.

12 D. Lane, Nat. Biotechnol., 2006, 24, 163-164.

13 N. Wang, Z. Zhao, Y. Lv, H. Fan, H. Bai, H. Meng, Y. Long, T. Fu, X. Zhang and W. Tan, Nano Res., 2014, 7, 1291-1301.

14 S. Luo, X. Tan, S. Fang, Y. Wang, T. Liu, X. Wang, Y. Yuan, H. Sun, Q. Qi and C. Shi, Adv. Funct. Mater., 2016, 26, 2826-2835.

15 H. He, S. Ji, Y. He, A. Zhu, Y. Zou, Y. Deng, H. Ke, H. Yang, Y. Zhao, Z. Guo and H. Chen, Adv. Mater., 2017, 29, 1606690.

16 X. Tan, S. Luo, L. Long, Y. Wang, D. Wang, S. Fang, Q. Ouyang, Y. Su, T. Cheng and C. Shi, Adv. Mater., 2017, 29, 1704196.

17 E. Delaey, F. van Laar, D. De Vos, A. Kamuhabwa, P. Jacobs and P. de Witte, J. Photochem. Photobiol., B, 2000, 55, 27-36.

18 K. Kassab, J. Photochem. Photobiol., B, 2002, 68, 15-22.

19 K. Yang, H. Xu, L. Cheng, C. Sun, J. Wang and Z. Liu, Adv. Mater., 2012, 24, 5586-5592.

20 Z. Meng, F. Wei, W. Ma, N. Yu, P. Wei, Z. Wang, Y. Tang, Z. Chen, H. Wang and M. Zhu, Adv. Funct. Mater., 2016, 26, 8231-8242.

21 N. Patel, P. Pera, P. Joshi, M. Dukh, W. A. Tabaczynski, K. E. Siters, M. Kryman, R. R. Cheruku, F. Durrani, J. R. Missert, R. Watson, T. Y. Ohulchanskyy, E. C. Tracy, H. Baumann and R. K. Pandey, J. Med. Chem., 2016, 59, 9774-9787.

22 M. Zheng, Y. Li, S. Liu, W. Wang, Z. Xie and X. Jing, ACS Appl. Mater. Interfaces, 2016, 8, 23533-23541.

23 J. Tian, L. Ding, H. Ju, Y. Yang, X. Li, Z. Shen, Z. Zhu, J. S. Yu and C. J. Yang, Angew. Chem., Int. Ed., 2014, 53, 9544-9549.

24 E. M. Sevick-Muraca, Annu. Rev. Med., 2012, 63, 217-231.

25 Y. Inoue, A. Saiura, J. Arita and Y. Takahashi, Ann. Surg., 2015, 262, e98-e99.
26 Z. Sheng, D. Hu, M. Zheng, P. Zhao, H. Liu, D. Gao, P. Gong, G. Gao, P. Zhang, Y. Ma and L. Cai, ACS Nano, 2014, 8, 12310-12322.

27 H. L. Jang, Y. S. Zhang and A. Khademhosseini, Nanomedicine, 2016, 11, 1495-1497.

28 C. Conte, S. Maiolino, D. S. Pellosi, A. Miro, F. Ungaro and F. Quaglia, Top. Curr. Chem., 2016, 370, 61-112.

29 S. S. Lucky, K. C. Soo and Y. Zhang, Chem. Rev., 2015, 115, 1990-2042.

30 W. Chen, J. Ouyang, H. Liu, M. Chen, K. Zeng, J. Sheng, Z. Liu, Y. Han, L. Wang, J. Li, L. Deng, Y. Liu and S. Guo, Adv. Mater., 2017, 29, 1603864.

31 J. Park, Q. Jiang, D. Feng, L. Mao and H. C. Zhou, J. Am. Chem. Soc., 2016, 138, 3518-3525.

32 J. Kim, J. Kim, C. Jeong and W. J. Kim, Adv. Drug Delivery Rev., 2016, 98, 99-112.

33 S. R. Banerjee, M. Pullambhatla, Y. Byun, S. Nimmagadda, C. A. Foss, G. Green, J. J. Fox, S. E. Lupold, R. C. Mease and M. G. Pomper, Angew. Chem., Int. Ed., 2011, 50, 9167-9170.

34 J. L. West and N. J. Halas, Annu. Rev. Biomed. Eng., 2003, 5, 285-292.

35 X. Huang, I. H. El-Sayed, W. Qian and M. A. El-Sayed, J. Am. Chem. Soc., 2006, 128, 2115-2120.

36 E. K. Lim, T. Kim, S. Paik, S. Haam, Y. M. Huh and K. Lee, Chem. Rev., 2015, 115, 327-394.

37 G. Chen, I. Roy, C. Yang and P. N. Prasad, Chem. Rev., 2016, 116, 2826-2885.

38 J. Huang, M. Guo, H. Ke, C. Zong, B. Ren, G. Liu, H. Shen, Y. Ma, X. Wang, H. Zhang, Z. Deng, H. Chen and Z. Zhang, Adv. Mater., 2015, 27, 5049-5056.

39 X. R. Song, X. Wang, S. X. Yu, J. Cao, S. H. Li, J. Li, G. Liu, H. H. Yang and X. Chen, Adv. Mater., 2015, 27, 3285-3291.

40 Y. Wang, T. Yang, H. Ke, A. Zhu, Y. Wang, J. Wang, J. Shen, G. Liu, C. Chen, Y. Zhao and H. Chen, Adv. Mater., 2015, 27, 3874-3882.

41 G. Lv, W. Guo, W. Zhang, T. Zhang, S. Li, S. Chen, A. S. Eltahan, D. Wang, Y. Wang, J. Zhang, P. C. Wang, J. Chang and X. J. Liang, ACS Nano, 2016, 10, 9637-9645.

42 K. K. Ng and G. Zheng, Chem. Rev., 2015, 115, 11012-11042.

43 D. Gao, L. Gao, C. Zhang, H. Liu, B. Jia, Z. Zhu, F. Wang and Z. Liu, Biomaterials, 2015, 53, 229-238.

44 C. Qian, J. Yu, Y. Chen, Q. Hu, X. Xiao, W. Sun, C. Wang, P. Feng, Q. D. Shen and Z. Gu, Adv. Mater., 2016, 28, 3313-3320.

45 H. S. Choi, W. Liu, P. Misra, E. Tanaka, J. P. Zimmer, I. B. Itty, M. G. Bawendi and J. V. Frangioni, Nat. Biotechnol., 2007, 25, 1165-1170.

46 C. Zhou, M. Long, Y. Qin, X. Sun and J. Zheng, Angew. Chem., Int. Ed., 2011, 50, 3168-3172.

47 J. Liu, P. Wang, X. Zhang, L. Wang, D. Wang, Z. Gu, J. Tang, M. Guo, M. Cao, H. Zhou, Y. Liu and C. Chen, ACS Nano, 2016, 10, 4587-4598.

48 Q. Chen, C. Liang, C. Wang and Z. Liu, Adv. Mater., 2015, 27, 903-910.

49 Q. Chen, C. Liang, X. Wang, J. He, Y. Li and Z. Liu, Biomaterials, 2014, 35, 9355-9362. 
50 P. Huang, P. Rong, A. Jin, X. Yan, M. G. Zhang, J. Lin, H. Hu, Z. Wang, X. Yue, W. Li, G. Niu, W. Zeng, W. Wang, K. Zhou and X. Chen, Adv. Mater., 2014, 26, 6401-6408.

51 J. Chen, Z. Sheng, P. Li, M. Wu, N. Zhang, X. F. Yu, Y. Wang, D. Hu, H. Zheng and G. P. Wang, Nanoscale, 2017, 9, 11888-11901.

52 F. M. Penha, E. B. Rodrigues, M. Maia, C. H. Meyer, E. P. Costa, E. Dib, E. Bechara, A. Lourenco, F. A. Lima, E. H. Freymuller and M. E. Farah, Ophthalmologica, 2013, 230, 59-67.

53 E. Engel, R. Schraml, T. Maisch, K. Kobuch, B. Konig, R. M. Szeimies, J. Hillenkamp, W. Baumler and R. Vasold, Invest. Ophthalmol. Visual Sci., 2008, 49, 1777-1783.
54 K. Polom, D. Murawa, Y. S. Rho, P. Nowaczyk, M. Hunerbein and P. Murawa, Cancer, 2011, 117, 4812-4822.

55 D. He, L. Hai, X. He, X. Yang and H. Li, Adv. Funct. Mater., 2017, 27, 1704089.

56 E. Friday, N. Koshy, V. K. Bhanderi and F. Torturro, Blood, 2010, 116, 1475.

57 H. Chen, A. Adam, Y. Cheng, S. Tang, J. Hartung and E. Bao, Mol. Med. Rep., 2015, 11, 2276-2284.

58 J. Liu, M. Yu, C. Zhou, S. Yang, X. Ning and J. Zheng, J. Am. Chem. Soc., 2013, 135, 4978-4981.

59 M. Perez-Hernandez, P. P. Del, S. G. Mitchell, M. Moros, G. Stepien, B. Pelaz, W. J. Parak, E. M. Galvez, J. Pardo and J. M. de la Fuente, ACS Nano, 2015, 9, 52-61. 